\title{
Consumer Environmental Awareness and Coordination in Closed-Loop Supply Chain
}

\author{
Yongmei Xu, Huaizhi Xie \\ School of Management, Jinan University, Guangzhou, China \\ Email: 2897054522@qq.com
}

Received 18 April 2016; accepted 28 June 2016; published 1 July 2016

Copyright $\odot 2016$ by authors and Scientific Research Publishing Inc.

This work is licensed under the Creative Commons Attribution International License (CC BY). http://creativecommons.org/licenses/by/4.0/

(c) (i) Open Access

\begin{abstract}
Considering the impact of products' eco-friendly level on demand, a two-stage closed-loop supply chain composed by a single manufacturer and a single retailer is constructed. Under both decentralized and centralized decision-making models, the paper deeply researches into the difference of supply chain system in economic benefits, environmental protection and social benefits, and a revenue sharing contract is applied to realize coordination between the manufacture and the retailer. The results show that the system of supply chain in centralized decision-making model is more efficient than that in decentralized decision-making model in economic benefits, environmental protection and social benefits, and the revenue sharing contract can coordinate the supply chain very well. Under two decision-making models, the products' eco-friendly level, return rate and profit of the node enterprise are positively correlated to the consumer environmental awareness, and negatively correlated to the price sensitivity as well as the cost parameter of green investment; the price is positively correlated to the scaling parameter of collecting and handling; return rate and profit of the node enterprise are negatively correlated, and products' eco-friendly level is irrelevant.
\end{abstract}

\section{Keywords}

Closed-Loop Supply Chain, Consumer Environmental Awareness, Products' Eco-Friendly Level, Coordination, Revenue Sharing Contract

\section{Introduction}

Abandonment of used products will not only cause serious environmental pollution, but also waste a lot of non-renewable resources. Since the 1980s, many countries and regions have formulated a series of laws, regulations and requirements for recycling used products. For example, Japan adopts the "consumer responsibility”, 
where manufacturers and distributors are responsible for collecting products, but consumers pay for the cost of treatment; the European Union and some of states and regions in United States adopt the "producer responsibility", where manufacturers are responsible for classification collection, recycling used electrical and electronic products and pay for related costs burden. Some of famous global manufacturing giants such as Hewlett-Packard, Xerox, Boeing, also proactively realize that remanufacturing used products will not only help to shape green image for company, but will be conductive to reduce the cost of production and improve the resource utilization.

A broader collection and comprehensive review of reverse supply chains and CLSC can be found in review articles [1] [2]. From a survey of the literature, reverse channel management of CLSC is one of the most important topics. Savaskan et al. introduced and compared three different reverse channels (i.e., the manufacturer collecting channel, the retailer collecting channel and the third-party collecting channel) and summarized some results from the three channels [3]. Savaskan and Wassenhove studied a two-stage CLSC consisting of a single manufacturer and two retailers and primarily discussed the manufacturer collecting model and the retailer collecting model [4]. Wei and Zhao considered a CLSC with one manufacturer and two competitive retailers and extended the manufacturer collecting model with fuzzy demand [5]. Hong and Yeh proposed a retailer collecting model, in which the retailer collected used products and the manufacturer cooperated with a third-party recycler to handle used products [6]. Contract research and coordination is another focus of Closed Loop Supply Chain. Cachon et al. discussed the strengths and limitations of revenue sharing contract in two-stage supply chain [7]. Giannoccaro researched the coordination of threes-echelon supply chains in decentralized decision-making model, showing that the revenue sharing contract is effective [8]. However, few works study others factor, such as promotion, advertising or consumer awareness, etc.

Actually, with the public's growing awareness of environmental protection and the deepening of understanding of supply chain management, people have gradually recognized that, in order to minimize the influence of the process of Supply-Production-Consumption on environment and resources, not only we should remanufacture used products, but should use more advanced green technology, reducing energy consumption, less or even no material likely to cause environmental pollution. Eco-friendly level is proposed in this context, which refers to the friendliness of products to human and environment [9], such as product content of harmful substances, energy consumption, recyclability, etc., and it has become an important factor affecting consumer purchase decisions. Green products are costlier to produce than those created conventionally, making these goods more expensive [10]. But, the higher the consumers' environmental awareness, the more the consumers are willing to pay higher prices for eco-friendly products [11]. Such awareness and willingness may vary significantly across industries, can change over time, and differ among consumer groups distinguished by demographics, knowledge, values, attitudes and behavior [12] [13]. Moon et al. collected consumer survey data in former West and East Berlin after the unification of Germany to address the issue of willingness to pay for foods produced with techniques consistent with environmental stewardship [14]. The results identified unique consumer groups by geographic region and age with respect to preferences for environmental attributes of agricultural products, with old consumers being less willing to pay the premium. In conclusion, Moon et al., stated that a stronger willingness to pay for green products would result in an immediate effect that the higher premium will induce more producers to convert to environmentally-friendly techniques [14].

Conrad developed a spatial duopoly model to determine how consumer environmental concern affects prices, product characteristics, and market shares of the competing firms [10], but assumed costs of production are equal and did not consider competition intensity levels. Fanelli [15] expanded on the work of Conrad [10] and Davies [16] to construct a two-stage duopoly game that allowed for the proportions of groups of consumers to not be fixed a priori, where the groups are defined by consumers who prefer buying the good by an ethical firm and the group of consumers who prefers buying the good by the lowest price firm. Swami et al. [17] and Liu et $a l$. [18] have studied the green supply chain by employing game-theoretical approach, but the works focused on the optimal decisions assuming a dominant manufacturer. Zhang et al. have studied the impact of consumer environmental awareness (CEA) on order quantities and channel coordination within a one-manufacturer and one-retailer supply chain [19].

Existing research results provided many useful references and enlightened ideas for further study of green products, but rarely combine consumer environmental awareness with closed-loop supply chain. In fact, we should not only carry out the recycling of used products, but also make production processes green, in order to construct supply chains with environmental benefits and high economic efficiency. Therefore, different from the former works, we consider consumer environmental awareness in closed-loop supply chain. In particular, we 
study three types of decision models: Model C-centralized decision-making model, Model D-decentralized decision-making model, and Model R-revenue sharing contract decision-making models in order to research following main questions:

(1) How are the wholesale price, the retail price, the eco-friendly improvement, the return rate and profits of decision-makers determined by the choice of different decision-making models?

(2) How do the consumers' environmental awareness influence the retail price, the eco-friendly improvement, the return rate and profits of decision-makers?

(3) How do the revenue sharing contract realize coordination of closed-loop supply chain?

We find that the system of supply chain in centralized decision-making model is more efficient than that in decentralized decision-making model in economic benefits, environmental protection and social benefits, and the revenue sharing contract (Model R) can coordinate the supply chain very well. In addition, in Model C and Model D, the retail price, return rate and profit of decision-makers are positively correlated to the consumer environmental awareness, and negatively correlated to the cost parameter of green investment as well as the scaling parameter of collecting and handling; the products' eco-friendly level, is positively correlated to the consumer environmental awareness, while negatively correlated to the cost parameter of green investment, but irrelevant with the scaling parameter of collecting and handling.

The remainder of the paper is organized as follows. In Section 2, we make some assumptions for the theoretical analysis. In Section 3, we model centralized decision-making model and decentralized decision-making model, and make comparison between two models. In Section 4, we introduce revenue sharing contract model to realize coordination in closed-loop supply chain. Section 5 presents a numerical example to illustrate some interesting insights. Section 6 concludes this paper.

\section{Model Assumptions and Notations}

We consider a two-echelon CLSC consisting of a single manufacturer, a single retailer. The manufacturer can manufacture products directly from raw materials, or remanufacture returned products into new products. We consider product categories in which there is no distinction, such as function, quality and packaging, between are manufactured product and a manufactured product. And the manufacturer engages in green innovation investment in order to improve eco-friendly level of products. The manufacturer sets the whole sale price paid to the retailer per unit of green product, while the retailer sets the selling price and sells the product to consumers.

The primary goal of this paper is to understand the implications of different decision-making models in CLSC considering consumer environmental awareness for optimal decisions and decision-makers' profits, then we introduce a revenue sharing contract to realize the cooperation between two parties. We also examine the sensitivity of the optimal return rate, eco-friendly level, retail price, and decision-makers' profits to various parameters to reveal the effect of interactions among the two parties indifferent decision-making models of CLSC. We use the notations in Table 1 throughout the paper.

We use the following notations throughout the paper.

\begin{tabular}{|c|c|}
\hline$c_{m}$ & Unit cost of manufacturing a new product. \\
\hline$c_{r}$ & Unit cost of remanufacturing a used product into a new product \\
\hline$m$ & Unit cost of collecting and handling a returned unit \\
\hline$\alpha$ & The return rate. \\
\hline$k$ & The scaling parameter. \\
\hline$w$ & Unit wholesale price of a new product. \\
\hline$p$ & Unit retail price of a new product. \\
\hline$h$ & The cost of green innovation investment parameter. \\
\hline$D$ & $\begin{array}{l}\text { The demand of new products in the market, where } \\
D=a+t e-b p, a \text { is the market size, } t \text { is the consumer environmental awareness, } \\
e \text { is the products' eco-friendly level and } b \text { is the elasticity of demand. }\end{array}$ \\
\hline
\end{tabular}


Without loss of generality, we make the following modeling assumptions which are often adopted by many classic papers.

Assumption 1. Producing a new product by using a used product is less costly than manufacturing a new one, i.e., $c_{r}<c_{m}$ and $c_{r}$ and $c_{m}$ are the same for all remanufactured and manufactured products respectively. And we assume that $m \leq c_{m}-c_{r}$, i.e., the fixed payment per unit concluding collecting and handling the used product is less than the savings generated per unit from remanufacturing [3] [20] [21].

Assumption 2. We characterize the reverse channel performance by $\alpha$, the return rate of used products from the customers. $\alpha$ denotes the fraction of current generation products remanufactured from returned units, i.e., $0 \leq \alpha \leq 1$. We model a as a function of the product collection effort, which is denoted by $I$, the investment in collection activities. Such investments can be considered as promotional expenditures undertaken by the manufacturer. To characterize the diminishing returns to investment, we use the cost structure $\alpha=\sqrt{I / k}$, where $k$ is scaling parameter, thus we can solve $I=k \alpha^{2}$ [3] [4].

Assumption 3. We characterize the eco-friendly level by $e$, which is a function of green innovation investment that is denoted by $I_{g}$. To characterize the relation between eco-friendly level and green innovation investment, we use the cost structure $e=\sqrt{I_{g} / h}$, where $h$ is a cost parameter, thus, we can solve $I_{g}=h e^{2}$ [19].

Assumption 4. We model the demand function as a multiplicative form $D(p, e)=a+t e-b p$, where $a$ is the market size, and $b$ is the elasticity of demand, and $t$ is the consumer environmental awareness [18] [19].

Assumption 5. In CLSC, the manufacturer has absolute channel power over the retailer, acting as a Stackelberg leader.

\section{Model Formulation and Solution}

This section primarily analyzes two decision-making models in a two-echelon CLCS considering the consumer environmental awareness, viz., Model C and model D, and their effect on optimal decisions and supply chain profits. Model C which is a benchmark model is analyzed to highlight benefits resulting from cooperation between two parties. We solve these models to obtain optimal decisions and compare the optimal decision variables concluding the wholesale price, the retail price, the return rate, the product eco-friendly level and total chain profits, in addition we research the sensitivity of these decision variables to reveal the effect of interactions among the two parties in different decision-making models of CLSC and provide some practical insights. All propositions and theorems can be proved (see Appendix for details).

\subsection{Model C-Centralized Decision-Making Model}

The centralized decision-making model (Model C) provides a benchmark scenario to compare the decentralized decision-making model with respect to the supply chain profits, the reverse channel performance, and the eco-friendly level. Because there is a single decision maker, the wholesale price $\mathrm{w}$ and the cost of collecting and handling $\mathrm{m}$ are irrelevant to the formulation $\mathrm{f}$ the objective function. Hence, the central planner optimizes.

$$
\pi^{C}=(a+t e-b p)\left(p-(1-\alpha) c_{m}-\alpha c_{r}-m \alpha-h e^{2}\right)-k \alpha^{2}
$$

Proposition 1. There exists a unique solution to the model C-centralized decision-making model. The optimal decision for the central planner is:

$$
\begin{gathered}
p^{C^{*}}=\left(2 a b h+t^{2}-\frac{k\left(4 b h\left(a-b c_{m}\right)+t^{2}\right)}{4 k-b\left(c_{m}-c_{r}-m\right)^{2}}\right) / 2 b^{2} h \\
e^{C^{*}}=\frac{t}{2 b h} \\
a^{C^{*}}=\frac{\left(4 a b h+t^{2}-4 b^{2} h c_{m}\right)\left(c_{m}-c_{r}-m\right)}{4 b h\left(4 k-b\left(c_{m}-c_{r}-m\right)^{2}\right)}
\end{gathered}
$$


The total profit of CLSC is:

$$
\pi^{C^{*}}=\frac{k\left(4 b h\left(a-b c_{m}\right)+t^{2}\right)^{2}}{16 b^{3} h^{2}\left(4 k-b\left(c_{m}-c_{r}-m\right)^{2}\right)}
$$

\subsection{Model D-Decentralized Decision-Making Model}

In the decentralized decision-making model, the manufacturer and the retailer are independent stakeholders who regard maximization of personal profit as the decision target. The manufacturer who is the game leader firstly determine the whole sale prices, the return rate and the eco-friendly level, then the retailer decide the market price as follow. Because the manufacturer has the first-mover advantage, so he will predict the response made by the retailer before making a decision, so we can use the method of backward induction to solving model.

The model D can be stated as:

$$
\begin{aligned}
\max \pi_{m}^{D} & =(a+t e-b p)\left(w-(1-\alpha) c_{m}-\alpha c_{r}-m \alpha-h e^{2}\right)-k \alpha^{2} \\
\text { s.t. } & p \arg \max \pi_{r}^{D}=(a+t * e-b * p)(p-w)
\end{aligned}
$$

Proposition 2. There exists a unique solution to the model D-decentralized decision-making model.

The optimal decision for the manufacturer is:

$$
\begin{gathered}
w^{D^{*}}=\left(2 a b h+t^{2}-\frac{2 k\left(4 b h\left(a-b c_{m}\right)+t^{2}\right)}{8 k-b\left(c_{m}-c_{r}-m\right)^{2}}\right) / 2 b^{2} h \\
e^{D^{*}}=\frac{t}{2 b h} \\
a^{D^{*}}=\frac{\left(4 b h\left(a-b c_{m}\right)+t^{2}\right)\left(c_{m}-c_{r}-m\right)}{4 b h\left(8 k-b\left(c_{m}-c_{r}-m\right)^{2}\right)}
\end{gathered}
$$

The optimal decision for the retailer is:

$$
p^{D^{*}}=\left(4 a b h+2 t^{2}-\frac{2 k\left(4 b h\left(a-b c_{m}\right)+t^{2}\right)}{8 k-b\left(c_{m}-c_{r}-m\right)^{2}}\right) / 4 b^{2} h
$$

The profit of the manufacturer is:

$$
\pi_{m}^{D^{*}}=\frac{k\left(4 b h\left(a-b c_{m}\right)+t^{2}\right)^{2}}{16 b^{3} h^{2}\left(8 k-b\left(c_{m}-c_{r}-m\right)^{2}\right)}
$$

The profit of the retailer is:

$$
\pi_{r}^{D^{*}}=\frac{k^{2}\left(4 b h\left(a-b c_{m}\right)+t^{2}\right)^{2}}{4 b^{3} h^{2}\left(8 k-b\left(c_{m}-c_{r}-m\right)^{2}\right)^{2}}
$$

The total profit of CLSC is:

$$
\pi^{D^{*}}=\frac{k\left(4 a b h+t^{2}-4 b^{2} h c_{m}\right)^{2}\left(12 k-b\left(c_{m}-c_{r}-m\right)\right)}{16 b^{3} h^{2}\left(8 k-b\left(c_{m}-c_{r}-m\right)\right)^{2}}
$$

\subsection{Comparison of Two Decision-Making Models}

Theorem 1. The return rate, eco-friendly level, retail price, and the total profit of CLSC in centralized decision-making model and decentralized decision-making model are related as: 


$$
\alpha^{D^{*}}<\alpha^{C^{*}}, e^{D^{*}}=e^{C^{*}}, p^{D^{*}}<p^{C^{*}}, \pi^{D^{*}}<\pi^{C^{*}} .
$$

See Appendix for Proof. Centralized decision-making not only help to reduce the market price, increase the recovery rate of the product, but also increase the overall supply chain profit level, indicating that cooperation has important economic, environmental and social benefits, but also shows the cooperation of consumers can be achieved, producers and social tripartite win-win situation.

Theorem 2. When the consumer environmental awareness, $t$, increases, the return rate, eco-friendly level, retail price, and the total profit of CLSC will increase.

$$
\frac{\partial p^{D^{*}}}{\partial t}>0, \frac{\partial \alpha^{D^{*}}}{\partial t}>0, \frac{\partial e^{D^{*}}}{\partial t}>0, \frac{\partial \pi_{r}^{D^{*}}}{\partial t}>0
$$

See Appendix for Proof. When $t$ increases, consumers are willing to pay higher prices for more eco-friendly products, which provides the entire supply chain with higher value-adding opportunity, the manufacturer will improve eco-friendly level of products, thus two parties are benefit from it. In addition, given others conditions remain unchanged, the more used product remanufactured into new product, the more profits two parties obtain, so the manufacturer will increase the return rate. On the other hand, the manufacture also increases green innovation investment resulting in higher retail price.

Theorem 3. When the cost parameter of green innovation investment, $h$, decreases, the return rate, ecofriendly level, retail price, and the total profit of CLSC will increase,

$$
\frac{\partial p^{D^{*}}}{\partial h}<0, \frac{\partial e^{D^{*}}}{\partial h}<0, \frac{\partial \alpha^{D^{*}}}{\partial h}<0, \frac{\partial \pi_{r}^{D^{*}}}{\partial h}<0
$$

See Appendix for Proof. The cost parameter of green innovation investment represents the technical difficulty of producing green products, it means that the more higher the cost parameter, the more difficult for production, while, the more small for it, the more easy. When $\mathrm{h}$ decreases, the manufacture produce green productions with an advanced technology, which provides the entire supply chain with the benefit resulting from technological progress, the manufacturer will improve eco-friendly level of products, thus two parties are benefit from it.

Theorem 4. When the scaling parameter of collection investment, $k$, decreases, the return rate, retail price, and the total profit of CLSC will increase, but the eco-friendly level will not be changed.

$$
\frac{\partial p^{D^{*}}}{\partial k}<0, \frac{\partial \alpha^{D^{*}}}{\partial k}<0, \frac{\partial \pi_{r}^{D^{*}}}{\partial k}<0, \frac{\partial e^{D^{*}}}{\partial k}=0
$$

See Appendix for Proof. The scaling parameter of collection investment represents the efficiency of collecting and handling used products, it means that the more higher scaling parameter, the more inefficient for collection, while, the more small for it, the more efficient. When $\mathrm{k}$ decreases, the manufacture collect and handle used productions with higher efficiency, which provides the entire supply chain with the benefit resulting from improvement of efficiency, the manufacturer will increase return rate, thus two parties are benefit from it.

But the eco-friendly level will not be changed. Based on optimal equation for the eco-friendly level, i.e. $e=\frac{t}{2 b h}$, we can know that given the elasticity of demand, $b$, keeps unchanged, when the consumer environmental awareness, $t$, increase, and the cost parameter of green investment, $h$, decrease simultaneously, the ecofriendly level will increase. The result imply that if we want to improve the eco-friendly level of products, from the outside, we should improve the environmental awareness of consumers, and the consumer environmental awareness must to be converted to green purchases rather than staying in ideas only; internally, enterprise should continue to improve the green technologies to reduce the cost of producing green products. This also shows that the goal of environmental protection cannot be achieved by one person alone, and it depends on consumers and producers together.

\section{Model R-Revenue-Sharing Contract}

When decentralized decision-making due to the presence of "double marginalization" effect, causing the level of the operating efficiency of the supply chain is difficult to achieve when the centralized decision-making. However, centralized decision-making is only an ideal situation, often by way of the actual operation of contracts to supply chain system Pareto optimization. Revenue-sharing contract is a contract is a widely used form, which requires the manufacturer to lower the wholesale price to the retailer, but the retailer to sell a certain percentage 
of revenue sharing with the manufacturer.

Thus, the function of the manufacturer and the retailer can be stated as:

$$
\begin{gathered}
\pi_{m}^{R}=(a+t e-p)\left(\lambda p+w-(1-\alpha) c_{m}-\alpha c_{r}-m \alpha-k e^{2}\right)-h \alpha^{2} \\
\pi_{r}^{R}=(a+t * e+k * s-b p)((1-\lambda) * p-w)
\end{gathered}
$$

Proposition 3. There exists a unique solution to the model R-revenue sharing contract model.

The optimal decision for the manufacturer is:

$$
\begin{gathered}
w^{R^{*}}=(1-\lambda)\left(a b h+t^{2}-b e h t-\frac{k\left(4 b h\left(a-b c_{m}\right)+t^{2}\right)}{4 k-b\left(c_{m}-c_{r}-m\right)^{2}}\right) / b^{2} h \\
e^{R^{*}}=\frac{t}{2 b h} \\
\alpha^{R^{*}}=\frac{\left(4 b h\left(a-b c_{m}\right)+t^{2}\right)\left(c_{m}-c_{r}-m\right)}{4 b h\left(4 k-b\left(c_{m}-c_{r}-m\right)^{2}\right)}
\end{gathered}
$$

The optimal decision for the retailer is:

$$
p^{R^{*}}=\left(2 a b h+t^{2}-\frac{k\left(4 b h\left(a-b c_{m}\right)+t^{2}\right)}{4 k-b\left(c_{m}-c_{r}-m\right)^{2}}\right) / 2 b^{2} h
$$

Profits of the manufacturer, the retailer and the CSCL are:

$$
\begin{gathered}
\pi_{m}^{R^{*}}=\frac{k\left(4 a b h+t^{2}-4 b^{2} h c_{m}\right)^{2}\left(4 k \lambda-b\left(c_{m}-c_{r}-m\right)^{2}\right)}{16 b^{3} h^{2}\left(4 k-b\left(c_{m}-c_{r}-m\right)^{2}\right)^{2}} \\
\pi_{r}^{R^{*}}=\frac{k^{2}(1-\lambda)\left(4 b h\left(a-b c_{m}\right)+t^{2}\right)^{2}}{4 b^{3} h^{2}\left(4 k-b\left(c_{m}-c_{r}-m\right)^{2}\right)^{2}}
\end{gathered}
$$

Theorem 5. In order to ensure the smooth implementation of revenue-sharing contract, it must also ensure that profits of the manufacturer and the retailer in model $\mathrm{R}$ are not less than profits they can get in decentralized decision-making model, i.e., $\pi_{m}^{R^{*}} \geq \pi_{m}^{D^{*}}$ and $\pi_{r}^{R^{*}} \geq \pi_{r}^{D^{*}}$, thus we can solve fluctuation range of sharing factor, $y$ :

$$
\left[b A^{2}+\frac{\left(4 k-b A^{2}\right)^{2}}{8 k-b A^{2}}\right] / 4 K \leq \lambda \leq 1-\left(\frac{4 k-b A^{2}}{8 k-b A^{2}}\right)^{2}
$$

where $A=c_{m}-c_{r}-m$.

\section{Numerical Examples}

In this section, we analyze the return rate, eco-friendly level, retail price, and the profits of decision-makers in three decision-making models, and further analyze the impact of revenue sharing factor on the profits of manufacturer and the retailer by a numerical example. We assume the parameters as follows: $a=200, b=5, t=6$, $c_{m}=10, c_{r}=3, m=2, h=2, k=600$.

Table 2 shows the return rate, eco-friendly level, retail price, and the profit of the manufacturer, the retailer and the system of CLCS in threes decision-making models. From Table 2, we can see: a) the profit of CLSC in centralized decision-making model is greater than that in decentralized decision-making model, and there are lower retailer price, higher return rate in former; b) the eco-friendly level will not be changed, no matter what 
Table 2. Comparison between three decision-making models.

\begin{tabular}{cccc}
\hline & Model D & Model C & Model R \\
\hline$p$ & 32.61 & 24.44 & 24.44 \\
$e$ & 24.87 & - & 3.41 \\
$\alpha$ & 0.33 & 0.33 & 0.33 \\
$\pi_{r}$ & $16.14 \%$ & $33.16 \%$ & $33.16 \%$ \\
$\pi_{m}$ & 300.06 & - & 506.84 \\
$\pi$ & 584.49 & - & 694.26 \\
\hline
\end{tabular}

decision-making model had be adopted, indicating that decision-making models have no effect on eco-friendly environmental level; c) the wholesale price in revenue-sharing contract is dropped dramatically comparing with in decentralized decision-making model, while the retail price, the return rate, the eco-friendly level and the profit of CLSC system all reach the level of centralized decision-making model, in addition, profits of the manufacturer and the retailer are more than that they can gain in decentralized decision-making model, showing that the revenue sharing contract not only realize the coordination in CLSC, but offers a sound mechanism of profit allocation between the manufacturer and the retailer. Above results from numerical analysis are consistent with

\section{Theorem 1.}

Profits of the manufacturer and the retailer in revenue sharing contract model are correlated with the sharing factor $y$. Figure 1 shows the impact of sharing factor on profits.

From Figure 1, we can see: when the sharing factor belonging to the manufacturer is increase, the profit of the manufacture will increase gradually, while, the profit of the retailer will decrease and vice versa. But the sharing factor varies within $(0.51,0.76)$ as long as, profits of the manufacturer and the retailer are more than that they can get in decentralized decision-making model, thus the cooperation between two parties is considerably stable, which suggests that the revenue sharing contract not only meets the constraint of incentive compatibility, but meet the constraint of individual rationality, realizing the coordination in CLSC considering the consumer environmental awareness very well. The feasibility of revenue sharing contract is also affirmed.

\section{Conclusions}

To achieve green production, not only to the recycling of waste products, we should also improve the green of the product in production. And the consumer's environmental awareness increases gradually confronting with the deterioration of environment. The consumers' environmental awareness affects consumers' willingness to pay higher prices for more eco-friendly products (Chitra, 2007) which can vary greatly across different industries and consumer groups, and can change over time (Laroche et al., 2001; Carlson, 2005). Based on this idea, we construct a two-echelon closed-loop supply chain consisting of a single manufacturer and a retailer. We are interested in the impact of consumers' environmental awareness and on decision makers in two different decision-making models, where the first decision-making model is the centralized decision-making model (Model C) that there is a center planner; the second decision-making model is decentralized decision-making model (Model D) that two parties are independent stakeholders. And we draw comparison between the Model C and the Model D. We also investigate how consumers' environmental awareness, the efficiency of green investment and the efficiency of collecting and handing influence the profits of the two decision makers in the two decision-making models.

We find that compared with Model C, although the eco-friendly level keeps constant, there is inefficiency in Model D, while Model R which is feasible and flexible can realize the coordination in CLCS. As consumers' environmental awareness increases and improvement of green technology, both the manufacturer and the retailer will benefit and the manufacturer will increase green investment and expand the scale of returning. Moreover, as the efficiency of collecting and handling increase, the profitability of two decision-makers and the return will increase, even which can change the eco-friendly level of products. In particular, the above results are of mana- 


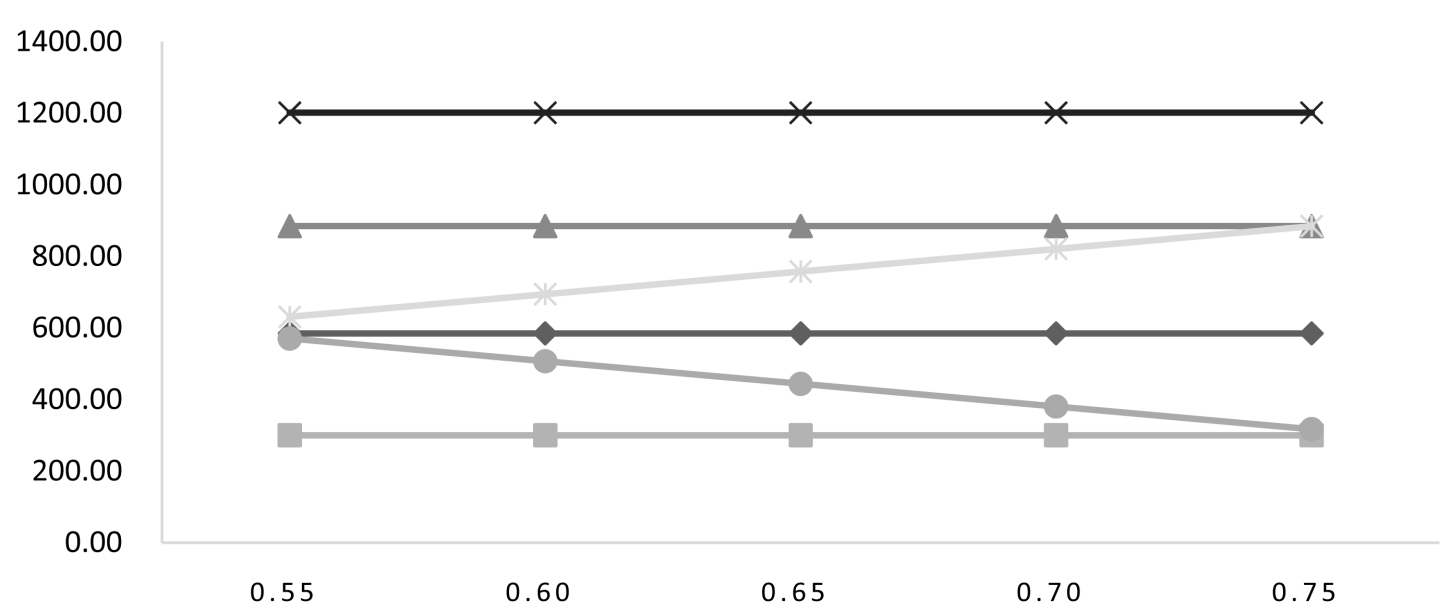

Sharing factor $\lambda$

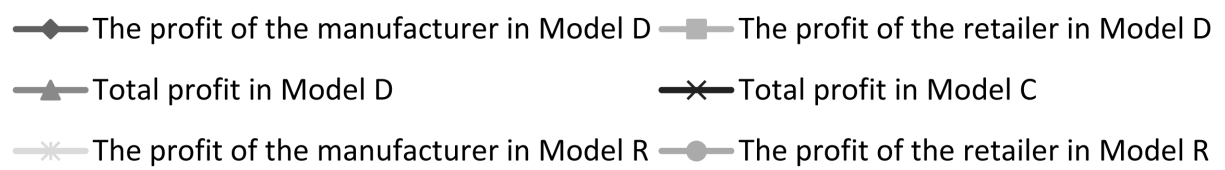

Figure 1. The manufacturer's and the retailer's profit in revenue sharing contract with $\lambda$ varying.

gerial relevance. First, cooperation between two parties has an impact on the retail price, return rates of used products, the total profit of CLSC. The mechanism of profit allocation is key to coordination. Moreover, the policy-makers, manufacturers, as well as retailers must understand that a major benefit of making and selling eco-friendly products and remanufacturing used products in new green products is from the demand enhancement and savings generated from remanufacturing due to the consumer environmental awareness. Hence, it is important for us to educate the public to increase environmental awareness of consumers so that improving eco-friendliness of products and the return rate becomes a value-adding activity. In addition, manufactures cannot ignore the progress in green production technology and the increasement of efficiency in collecting and handing used products. The policy-makers can also do something, such as offering subsidiary for manufacturers' green innovation activities and intensifying the investment in collecting infrastructure to ease the burden of recyclers.

It should be noted that this paper only studies a two-echelon supply chain consisting of a single manufacturer and a single retailer. The practical supply chain network in reality is often more complicated than that in our model, for example, a manufacturer may be faced with many competitive retailers, while a retailer also may face a number of competitive manufacturers who produce alternative green products. All of these questions are our future works.

\section{Acknowledgments}

We are grateful to the associate editor and the two anonymous reviewers for their valuable comments and useful suggestions which are all valuable and very helpful for revising and improving our paper.

\section{References}

[1] Guide Jr., V.D.R. and Van Wassenhove, L.N. (2009) OR FORUM-The Evolution of Closed-Loop Supply Chain Research. Operations Research, 57, 10-18. http://dx.doi.org/10.1287/opre.1080.0628

[2] Govindan, K., Soleimani, H. and Kannan, D. (2015) Reverse Logistics and Closed-Loop Supply Chain: A Comprehensive Review to Explore the Future. European Journal of Operational Research, 240, 603-626. http://dx.doi.org/10.1016/j.ejor.2014.07.012

[3] Savaskan, R.C., Bhattacharya, S. and Van Wassenhove, L.N. (2004) Closed-Loop Supply Chain Models with Product Remanufacturing. Management Science, 50, 239-252. http://dx.doi.org/10.1287/mnsc.1030.0186 
[4] Savaskan, R.C. and Van Wassenhove, L.N. (2006) Reverse Channel Design: The Case of Competing Retailers. Management Science, 52, 1-14. http://dx.doi.org/10.1287/mnsc.1050.0454

[5] Wei, J. and Zhao, J. (2011) Pricing Decisions with Retail Competition in a Fuzzy Closed-Loop Supply Chain. Expert Systems with Applications, 38, 11209-11216. http://dx.doi.org/10.1016/j.eswa.2011.02.168

[6] Hong, I. and Yeh, J. (2012) Modeling Closed-Loop Supply Chains in the Electronics Industry: A Retailer Collection Application. Transportation Research Part E: Logistics and Transportation Review, 48, 817-829. http://dx.doi.org/10.1016/j.tre.2012.01.006

[7] Cachon, G.P. and Lariviere, M.A. (2005) Supply Chain Coordination with Revenue-Sharing Contracts: Strengths and Limitations. Management Science, 51, 30-44. http://dx.doi.org/10.1287/mnsc.1040.0215

[8] Giannoccaro, I. and Pontrandolfo, P. (2004) Supply Chain Coordination by Revenue Sharing Contracts. International Journal of Production Economics, 89, 131-139. http://dx.doi.org/10.1016/S0925-5273(03)00047-1

[9] Dangelico, R.M. and Pontrandolfo, P. (2010) From Green Product Definitions and Classifications to the Green Option Matrix. Journal of Cleaner Production, 18, 1608-1628. http://dx.doi.org/10.1016/j.jclepro.2010.07.007

[10] Conrad, K. (2005) Price Competition and Product Differentiation When Consumers Care for the Environment. Environmental and Resource Economics, 31, 1-19. http://dx.doi.org/10.1007/s10640-004-6977-8

[11] Chitra, K. (2007) In Search of the Green Consumers: A Perceptual Study. Journal of Services Research, 7, $173-191$.

[12] Laroche, M., Bergeron, J. and Barbaro-Forleo, G. (2001) Targeting Consumers Who Are Willing to Pay More for Environmentally Friendly Products. Journal of Consumer Marketing, 18, 503-520. http://dx.doi.org/10.1108/EUM0000000006155

[13] Carlson, D.K. (2005) Public Priorities: Environment vs. Economic Growth. Gallup Poll. http://www.gallup.com/poll/15820/Public-Priorities-Environment-vs-Economic-Growth.aspx

[14] Moon, W., et al. (2002) Willingness to Pay for Environmental Practices: Implications for Eco-Labeling. Land Economics, 78, 88-102. http://dx.doi.org/10.2307/3146925

[15] Fanelli, D. (2008) A Two-Stage Duopoly Game with Ethical Labeling and Price Competition When Consumers Differ in Preferences. University Library of Munich, Munich.

[16] Davies, R.B. (2005) Abstinence from Child Labor and Profit Seeking. Journal of Development Economics, 76, 251263. http://dx.doi.org/10.1016/j.jdeveco.2003.11.004

[17] Swami, S. and Shah, J. (2013) Channel Coordination in Green Supply Chain Management. Journal of the Operational Research Society, 64, 336-351. http://dx.doi.org/10.1057/jors.2012.44

[18] Liu, Z.L., Anderson, T.D. and Cruz, J.M. (2012) Consumer Environmental Awareness and Competition in Two-Stage Supply Chains. European Journal of Operational Research, 218, 602-613. http://dx.doi.org/10.1016/j.ejor.2011.11.027

[19] Zhang, L., Wang, J. and You, J. (2015) Consumer Environmental Awareness and Channel Coordination with Two Substitutable Products. European Journal of Operational Research, 241, 63-73. http://dx.doi.org/10.1016/j.ejor.2014.07.043

[20] Giutini, R. and Gaudette, K. (2003) Remanufacturing: The Next Great Opportunity for Boosting US Productivity. Business Horizons, 46, 41-48. http://dx.doi.org/10.1016/S0007-6813(03)00087-9

[21] Zu-Jun, M., Zhang, N., Dai, Y. and Hu, S. (2016) Managing Channel Profits of Different Cooperative Models in Closed-Loop Supply Chains. Omega, 59, 251-262. http://dx.doi.org/10.1016/j.omega.2015.06.013 


\section{Appendix}

\section{Proof of proposition 1}

To have an interior point solution for $\pi, \pi$ should satisfy the first-order conditions

$$
\frac{\partial \pi^{C}}{\partial p}=0 \text { and } \frac{\partial \pi^{C}}{\partial e}=0 \text { and } \frac{\partial \pi^{C}}{\partial \alpha}=0
$$

Thus, the first-order condition can be solved as

$$
\left\{\begin{array}{l}
p^{C^{*}}=\left(2 a b h+t^{2}-\frac{k\left(4 b h\left(a-b c_{m}\right)+t^{2}\right)}{4 k-b\left(c_{m}-c_{r}-m\right)^{2}}\right) / 2 b^{2} h \\
e^{C^{*}}=\frac{t}{2 b h} \\
a^{C^{*}}=\frac{\left(4 a b h+t^{2}-4 b^{2} h c_{m}\right)\left(c_{m}-c_{r}-m\right)}{4 b h\left(4 k-b\left(c_{m}-c_{r}-m\right)^{2}\right)}
\end{array}\right.
$$

Then, we can calculate the Hessian matrix as follows:

$$
H=\left(\begin{array}{ccc}
-2 h(a-b p+3 e t) & -t\left(m-c_{m}+c_{r}\right) & 2 b e h+t \\
-t\left(m-c_{m}+c_{r}\right) & -2 k & b\left(m-c_{m}+c_{r}\right) \\
2 b e h+t & b\left(m-c_{m}+c_{r}\right) & -2 b
\end{array}\right)
$$

Since $a>b c_{m}$ and $k>0, t>0, h>0$, we can obtain

$$
|H|=-k\left(4 b h\left(a-b c_{m}\right)+t^{2}\right)<0 \text {, and }\left|H_{1}\right|=-2 h(a-b p+3 e t)<0
$$

Hence, $\pi^{C}$ is jointly concave in $p, e$ and $\alpha$, and taking the optimal decisions into the profit function of the central planner, i.e., $\pi^{C}$, we can solve the optimal profit, i.e., $\pi^{C^{*}}$.

Proof of proposition 2

Given a wholesale price $w$, the eco-friendly level $e$ and the return rate $\alpha$, the retailer decides optimal decisions on the retailing price $p$. We can solve response function of the retailer:

$$
p=(a+e t+b w) / 2 b
$$

Taking it on the profit function of the retailer yields

$$
\pi_{m}^{D}=-k \alpha^{2}-\frac{1}{2}(a+e t-b w)\left(e^{2} h-w+m \alpha-(-1+\alpha) c_{m}+\alpha c_{r}\right)
$$

According to the method consistent with the proof in Proposition 1, it is easy to prove that $\pi_{m}^{D}$ is jointly concave in $w, e$ and $\alpha$. Thus, we can solve the optimal decisions of the manufacturer, i.e.,

$$
\left\{\begin{array}{l}
w^{D^{*}}=\left(2 a b h+t^{2}-\frac{2 k\left(4 b h\left(a-b c_{m}\right)+t^{2}\right)}{8 k-b\left(c_{m}-c_{r}-m\right)^{2}}\right) / 2 b^{2} h \\
e^{D^{*}}=\frac{t}{2 b h} \\
a^{D^{*}}=\frac{\left(4 b h\left(a-b c_{m}\right)+t^{2}\right)\left(c_{m}-c_{r}-m\right)}{4 b h\left(8 k-b\left(c_{m}-c_{r}-m\right)^{2}\right)}
\end{array}\right.
$$

And taking above decisions into the response function of the retailer, we can sole the optimal decision of the retailer: 


$$
p^{D^{*}}=\left(4 a b h+2 t^{2}-\frac{2 k\left(4 b h\left(a-b c_{m}\right)+t^{2}\right)}{8 k-b\left(c_{m}-c_{r}-m\right)^{2}}\right) / 4 b^{2} h
$$

So, we can easily solve the optimal profits of the manufacturer and the retailer, i.e., $\pi_{m}^{D^{*}}$ and $\pi_{r}^{D^{*}}$.

Proof of theorem 1

Note that in the proof of Proposition 1, we solve $a^{C^{*}}=\frac{\left(4 a b h+t^{2}-4 b^{2} h c_{m}\right)\left(c_{m}-c_{r}-m\right)}{4 b h\left(4 k-b\left(c_{m}-c_{r}-m\right)^{2}\right)}$. In order to guarantee $0<a^{C^{*}}<1$ (Assumption 2), we can extended following assumption:

$$
\left\{\begin{array}{l}
a>b c_{m} \\
k>\left[A\left(b A+a-b c_{m}+t^{2} / 4 b h\right)\right] / 4
\end{array}\right.
$$

where $A=c_{m}-c_{r}-m$, which represent that the market size is considerable and the investment of collection by the manufacture is enough. Obviously, this assumption is very realistic. Given above condition, we can easily prove:

$$
\begin{gathered}
\frac{\partial p^{C^{*}}}{\partial t}=\frac{t}{b^{2} h} \frac{7 k-b A^{2}}{8 k-b A^{2}}>0, \frac{\partial e^{C^{*}}}{\partial t}=\frac{1}{2 b h}>0, \\
\frac{\partial \alpha^{C^{*}}}{\partial t}=\frac{t A}{2 b h\left(8 k-b A^{2}\right)}>0, \frac{\partial \pi_{r}^{C^{*}}}{\partial t}=\frac{k^{2} t\left(4 b h\left(a-b c_{m}\right)+t^{2}\right)}{b^{3} h^{2}\left(8 k-b A^{2}\right)^{2}}>0
\end{gathered}
$$

Thus, theorem 1 is proved.

According to the method consistent with the proof in Therom1, it is easy to prove Therom 2, 3 and 4.

Proof of Proposition 3

The first-order condition of the retailer in Model R can be stated as

$$
p^{R^{*}}=\frac{-a-e t-b w+a \lambda+e t \lambda}{2 b(-1+\lambda)}
$$

In order to realize coordination between two parties will necessitate following conditions:

$$
p^{R^{*}}=p^{C^{*}}, e^{R^{*}}=e^{C^{*}} \text { and } \alpha^{R^{*}}=\alpha^{C^{*}}
$$

Thus, we can solve the optimal decisions in Model R.

\section{Scientific Research Publishing}

\section{Submit or recommend next manuscript to SCIRP and we will provide best service for you:}

Accepting pre-submission inquiries through Email, Facebook, Linkedin, Twitter, etc A wide selection of journals (inclusive of 9 subjects, more than 200 journals)

Providing a 24-hour high-quality service

User-friendly online submission system

Fair and swift peer-review system

Efficient typesetting and proofreading procedure

Display of the result of downloads and visits, as well as the number of cited articles

Maximum dissemination of your research work

Submit your manuscript at: http://papersubmission.scirp.org/ 